\title{
Differential intracellular calcium influx, nitric oxide production, ICAM-1 and IL8 expression in primary bovine endothelial cells exposed to nonesterified fatty acids
}

\author{
Anitsi Loaiza ${ }^{1}$, María D. Carretta ${ }^{1}$, Anja Taubert ${ }^{2}$, Carlos Hermosilla ${ }^{2}$, María A. Hidalgo ${ }^{1}$ and Rafael A. Burgos ${ }^{1 *}$
}

\begin{abstract}
Background: Nonesterified fatty acids (NEFAs) are involved in proinflammatory processes in cattle, including in the increased expression of adhesion molecules in endothelial cells. However, the mechanisms underlying these effects are still unknown. The aim of this study was to assess the effects of NEFAs on the intracellular calcium $\left(\mathrm{Ca}^{2+}{ }_{\mathrm{i}}\right)$ influx, nitric oxide production, and ICAM-1 and IL-8 expression in primary bovine umbilical vein endothelial cells (BUVECS).

Results: Myristic (MA), palmitic (PA), stearic (SA), oleic $(\mathrm{OA})$ and linoleic acid $(\mathrm{LA})$ rapidly increased $\mathrm{Ca}^{2+}{ }_{\mathrm{i}}$. The calcium response to all tested NEFAs showed an extracellular calcium dependence and only the LA response was significantly inhibited until the intracellular calcium was chelated. The $\mathrm{EC}_{50}$ values for MA and LA were $125 \mu \mathrm{M}$ and $37 \mu \mathrm{M}$, respectively, and the MA and LA effects were dependent on calcium release from the endoplasmic reticulum stores and on the L-type calcium channels. Only the calcium response to MA was significantly reduced by GW1100, a selective G-protein-coupled free fatty acid receptor (GPR40) antagonist. We also detected a functional FFAR1/GPR40 protein in BUVECs by using western blotting and the FFAR1/GPR40 agonist TAK-875. Only LA increased the cellular nitric oxide levels in a calcium-dependent manner. LA stimulation but not MA stimulation increased ICAM-1 and IL-8-expression in BUVECs. This effect was inhibited by GW1100, an antagonist of FFAR1/ GPR40, but not by U-73122, a phospholipase C inhibitor.

Conclusions: These findings strongly suggest that each individual NEFA stimulates endothelial cells in a different way, with clearly different effects on intracellular calcium mobilization, NO production, and IL-8 and ICAM-1 expression in primary BUVECs. These findings not only extend our understanding of NEFA-mediated diseases in ruminants, but also provide new insight into the different molecular mechanisms involved during endothelial cell activation by NEFAs.
\end{abstract}

Keywords: Nonesterified fatty acid, Primary bovine endothelial cell, Interleukin 8, Intercellular adhesion molecule 1, Calcium flux

\section{Background}

The levels of nonesterified fatty acids (NEFAs) in bovine plasma increase during transition periods, such as after calving and during early lactation [1]. During these stages, a negative energy balance is generated, which is mainly characterized by an increased release of NEFAs from adipose tissues into the plasma [2]. Elevated plasma NEFA

\footnotetext{
* Correspondence: rburgos1@uach.cl

${ }^{1}$ Instituto de Farmacología, Facultad de Ciencias Veterinarias, Universidad

Austral de Chile, Valdivia, Chile

Full list of author information is available at the end of the article
}

concentrations have recently been related to the incidence of metabolic and infectious bovine diseases, including fatty hepatitis, metabolic ketosis, mastitis, and endometritis, which cause high economic losses to the cattle industry worldwide [2, 3]. Therefore, NEFAs directly affect tissue/ organ functions, and even more importantly, indirectly affect the bovine innate immune system, as previously reported [4].

Endothelial cells are highly immunoreactive cells that synthesize a broad spectrum of chemokines, cytokines, and adhesion molecules, and therefore play an active 
part in early proinflammatory reactions [5]. Consistent with this, the exposure of primary bovine aortic endothelial cells (BAECs) to a mixture of NEFAs for $24 \mathrm{~h}$ altered their membrane phospholipid profile, increasing the stearic acid concentration and reducing the polyunsaturated fatty acid concentrations [6]. In the same study, $0.75 \mathrm{mM}$ NEFA increased the expression of the proinflammatory cytokines interleukin 6 (IL-6) and IL-8, and the adhesion molecules intercellular adhesion molecule 1 (ICAM-1) and vascular cell adhesion molecule 1 (VCAM-1) in BAECs [6], which interact with other immunocompetent cells, such as neutrophils. Although the effects of NEFAs on bovine leukocytes and endothelial cells have been examined previously $[1,7,8]$, the exact molecular mechanisms are still poorly understood.

It has long been accepted that the hydrophobic nature of lipids allows them to activate cells after they enter them, e.g., through membrane transport mechanisms $[9,10]$. However, a G-protein-coupled free fatty acid receptor known as GPR40 or free fatty acid receptor 1 (FFAR1) has recently been described [11]. This novel free fatty acid receptor recognizes saturated and unsaturated medium- and long-chain fatty acids, and the human, rat, and mouse isoforms of FFAR1/GPR40 have been described $[11,12]$. Recently, the effects of FFAR1/GPR40 agonists, such as oleic acid (OA) and linoleic acid (LA), have been demonstrated in epithelial mammary cells [13] and neutrophils $[14,15]$. Consequently, primary bovine tissues are thought to be susceptible to NEFA exposure primarily via the corresponding bovine free fatty acid receptor 1 (bFFA1R/bGPR40). Based on this evidence, we evaluated whether different types of NEFAs can rapidly modify the intracellular calcium response in primary bovine endothelial cells exposed to single fatty acids and to study in more detail the molecular mechanisms involved in this endothelial activation.

\section{Results}

Acute treatment with NEFAs does not affect the viability of primary bovine umbilical vein endothelial cells (BUVECs)

Cells exposed to $300 \mu \mathrm{M}$ LA, palmitic acid (PA), OA, myristic acid (MA), or stearic acid (SA) showed no significant difference in the propidium iodide signal for 15 min when compared with untreated cells (basal condition) (see Additional file 1). Similar results were observed in BUVECs exposed to $1 \%$ vehicle (DMSO or ethanol) for the same period. Therefore, exposure to $300 \mu \mathrm{M}$ of each fatty acid did not increase BUVEC death any more than Triton X-100 treatment, used as the positive control. We demonstrated that $0.3 \mathrm{mM}$ EGTA, $50 \mu \mathrm{M}$ BAPTA-AM or each NEFA plus EGTA or BAPTA did not affect the viability of BUVECs (see Additional file 1). These results clearly demonstrate that these fatty acid concentrations and exposure time have no toxic effects on BUVECs.
NEFAs increase the intracellular calcium influx in BUVECs The intracellular calcium response in primary bovine endothelial cells was evaluated in BUVECs exposed acutely to different NEFAs for $100 \mathrm{~s}$. The calcium signal increased quickly after stimulation with $300 \mu \mathrm{M}$ MA, PA, SA, or OA, with similar kinetics, and the intracellular calcium levels reached a new steady state (Fig. 1a-d, black traces). In contrast, LA caused a slow but constant increase in intracellular calcium (Fig. 1e). To identify the roles of intracellular and extracellular calcium, we used the well-known calcium-chelating agents BAPTA-AM and EGTA. Incubation with BAPTA-AM reduced the slope of calcium increase by more than $50 \%$ in all cases, except for LA (see Additional file 2). However, this did not affect the area under the curve (AUC) of calcium flux (Fig. 1f-i). Moreover, the BAPTA-AM treatment significantly reduced the area under the curve (AUC) only in cells previously exposed to LA (Fig. 1j). The latter suggests that the increase in calcium induced by LA is dependent on intracellular and extracellular calcium mobilization. In our experiments, the NEFA-mediated increase in calcium was significantly inhibited in the presence of EGTA (as illustrated in Fig. 1a-e, light gray traces; Fig. 1f-j), suggesting that the increase in calcium in the whole experiment is mainly depended on calcium influx.

\section{Mechanisms of MA and LA effects on intracellular calcium release in BUVECs}

We investigated the potential differential responses of BUVECs to MA and LA, exemplary for saturated and unsaturated NEFAs, respectively. To investigate the mechanism of the calcium increase, we first constructed doseresponse curves of the calcium signal after stimulation with MA and LA, and obtained half-maximal effective concentrations $\left(\mathrm{EC}_{50}\right)$ of 125 and $37 \mu \mathrm{M}$, respectively (Fig. 2a, d). We then used concentrations close to the $\mathrm{EC}_{50}$ values to assess the mechanisms involved in calcium flux. Upon stimulation with $100 \mu \mathrm{M}$ MA, BUVECs showed a rapid increase in calcium, which decreased until a new steady state was reached after $30 \mathrm{~s}$ (Fig. 2b, inset). In contrast, stimulation with $30 \mu \mathrm{M}$ LA caused a sustained increase in calcium within the first $100 \mathrm{~s}$ (see Fig. 2e, inset), and a steady state was observed after stimulation for $200 \mathrm{~s}$ (data not shown).

To evaluate whether FFAR1/GPR40 actively participates in the calcium increase induced by MA or LA, we used its antagonist GW1100, as previously reported [16]. The response produced by $100 \mu \mathrm{M}$ MA was inhibited by $59 \%$ by $10 \mu \mathrm{M}$ GW1100 (see Fig. 2c). This was also observed when other saturated fatty acids were used in our in vitro bovine endothelial cell system, and GW1100 inhibited 66 and $63 \%$ of the calcium response induced by $300 \mu \mathrm{M}$ PA and SA, respectively (see Additional file 3). In 


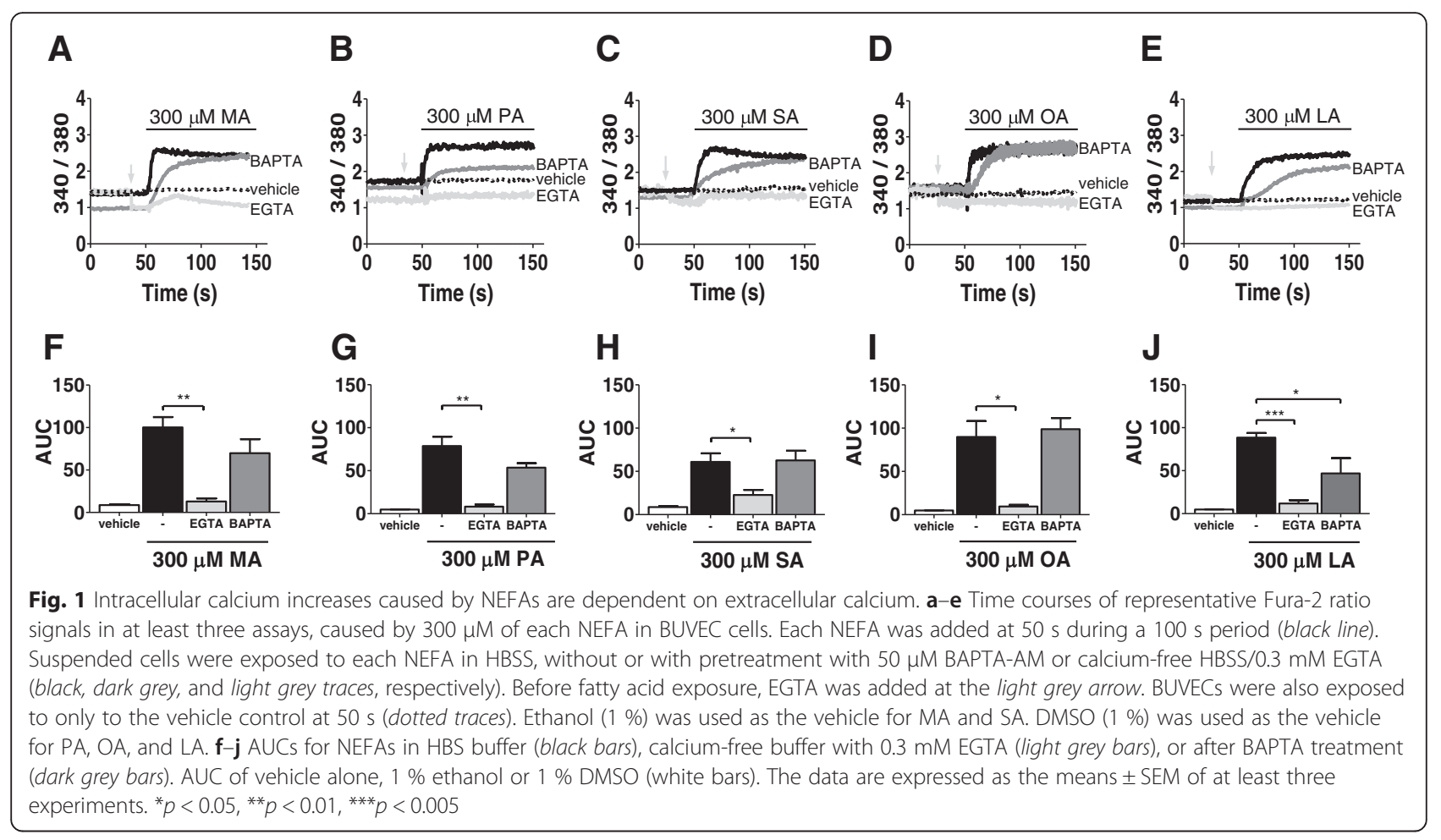

contrast, the calcium influx response to $30 \mu \mathrm{M}$ LA was not affected by GW1100 (Fig. 2f), and a similar response was observed when OA was used as the unsaturated fatty acid (see Additional file 3).

To assess the role of the G-protein $\mathrm{G \alpha}_{\mathrm{i} / \mathrm{o}}$, phospholipase $\mathrm{C}$ (PLC), and the inositol triphosphate $\left(\mathrm{IP}_{3}\right)$ receptors/calcium-operated channels induced by MA and LA, we used pertussis toxin (PTX) [17], U73122 [18], and 2APB [19-21], respectively. We demonstrated that preincubation with $100 \mathrm{ng} / \mathrm{ml}$ PTX for $16 \mathrm{~h}$ did not inhibit the calcium influx induced either by MA or LA fatty acids in BUVECs, which suggests that $G \alpha_{i / o}$ does not participate in this type of response. The mobilization of calcium by LA was reduced by $4 \mu \mathrm{M}$ U73122, but the effect of MA was not affected by treatment with the PLC inhibitor. 2-APB $(100 \mu \mathrm{M})$ reduced both the MA- and LA-mediated increases in calcium by 25 and $23 \%$, respectively (see Fig. 2c and f).

There is some evidence that fatty acids can directly and indirectly activate the L-type calcium channels (LTCCs) in HEK293, COS-7 and rat insulinoma INS-1E cells in vitro $[22,23]$. However, the participation of LTCCs in the calcium increase induced by MA or LA in BUVECs has not been evaluated. Therefore, we investigated whether these channels participate in the calcium increase induced by MA or LA stimulation. Our results show that the LTCC blocker nifedipine $(20 \mu \mathrm{M})$ inhibited the increases in calcium induced by MA and LA by 45 and $22 \%$, respectively (Fig. $2 \mathrm{c}$ and f). These results suggest that LTCCs participate in the increases in calcium caused by saturated and unsaturated fatty acids in BUVECS.

\section{FFAR1/GPR40 expression and activity}

To examine FFAR1/GPR40 protein expression in BUVECs, we used western blotting and immunofluorescence assays directed against the conserved epitope of bovine GPR40, as described elsewhere [14]. An immunoblotting analysis of the total protein extracts of BUVECs showed a band with an apparent molecular size of $23-\mathrm{kDa}$, lower than expected but similar to that observed in LoVo cells, which were used as the positive control, as suggested by the manufacturer of the anti-GPR40 antibody (Fig. 3a). The same antibody was used for the immunofluorescence assays of BUVECs, which detect the internal region of human GPR40, and therefore the intracellular and plasma membrane distribution (Fig. 3b). To confirm that the FFAR1/GPR40 protein is in its active form in BUVECs, we also measured the calcium signal separately with two known FFAR1/GPR40 agonists, TAK-875 [24] and GW9508 [16]. TAK-875 increased the intracellular calcium in a dosedependent manner (Fig. 3c, d), whereas GW9508 did not change the calcium signal at either low $(10,50 \mu \mathrm{M})$ or high concentrations (100 $\mu \mathrm{M}$; data not shown).

\section{LA increases nitric oxide (NO) production}

To assess whether NEFAs affect NO production in the endothelium, we exposed BUVECs to MA, SA, PA, OA, 


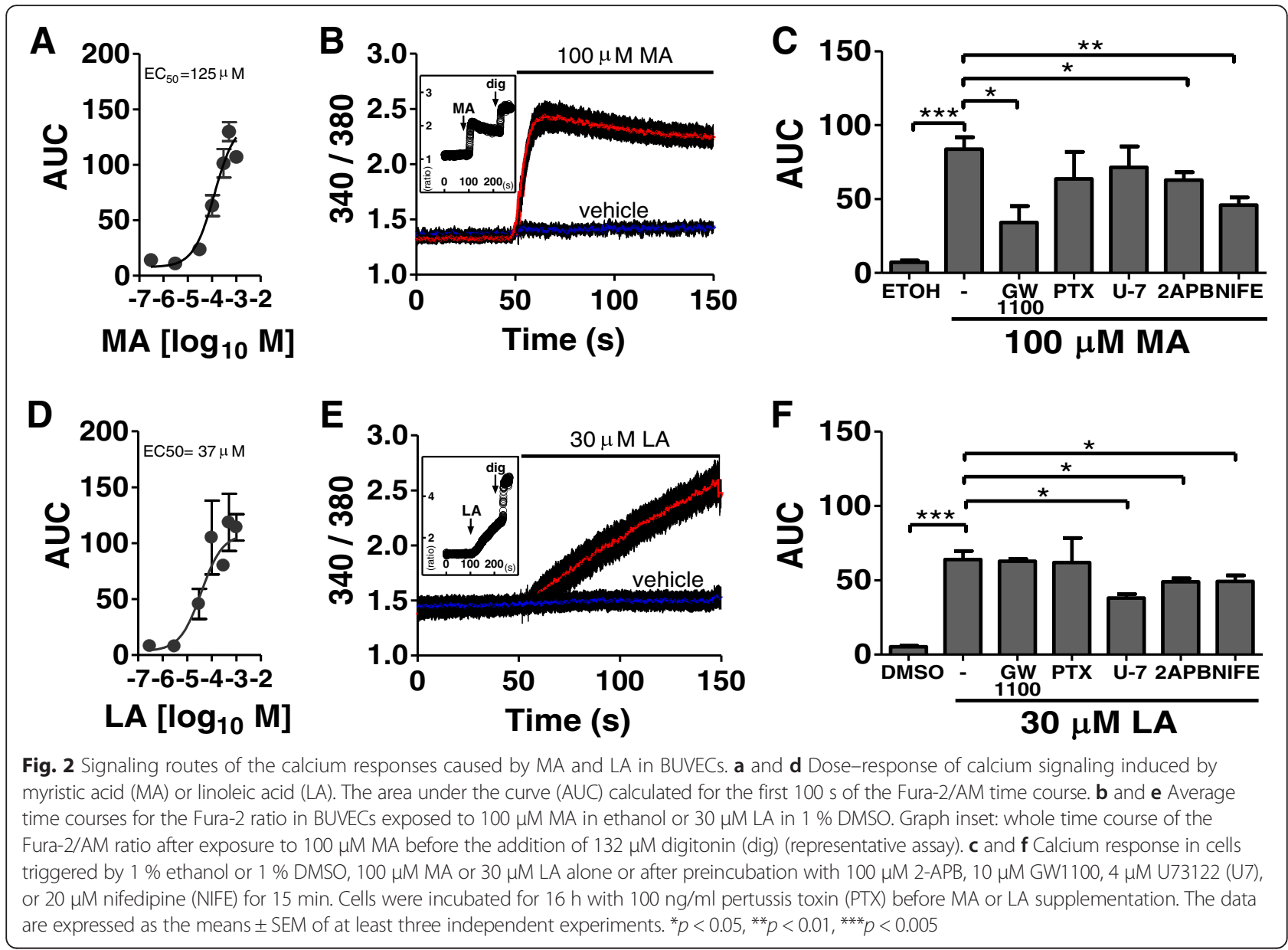

or LA and evaluated the cells for NO production using DAF-FM signals. Only LA significantly increased the DAF-FM fluorescence intensity in BUVEC monolayers. As illustrated in Fig. 4a, the DAF-FM signal increased approximately 1.5-fold in LA-exposed BUVECs compared with the signal in cells treated with vehicle (DMSO). The increase in NO induced by LA was reduced by $25 \%$ when the cells were treated with $100 \mu \mathrm{M}$ L-NAME, a potent endothelial nitric oxide synthase (eNOS) inhibitor (Fig. 4c). This indicates that LA activates eNOS in primary bovine endothelial cells. Treatment with BAPTA, EGTA, or BAPTA plus EGTA reduced the increase in NO induced by LA by 50,91 , and $86 \%$, respectively (Fig. 4b). In contrast, neither $4 \mu \mathrm{M}$ U73122, $10 \mu \mathrm{M}$ GW1100, $100 \mu \mathrm{M} 2$ $\mathrm{APB}, 20 \mu \mathrm{M}$ nifedipine, nor $100 \mathrm{ng} / \mathrm{ml}$ PTX reduced the LA-mediated increase in NO (data not shown).

\section{LA but not MA increases ICAM-1 and IL-8 mRNA expression}

Because only LA effectively increased eNOS activity in BUVECs, we tested whether LA also affects ICAM-1 or IL-8 expression. Only LA induced the expression of ICAM-1 and IL-8 mRNAs in BUVECs, and LA-induced
IL-8 expression was significantly inhibited by GW1100. However, the expression of ICAM-1 was not reduced by treatment with the FFAR1/GPR40 antagonist (Fig. 5).

\section{Discussion}

The NEFA levels in blood plasma are particularly elevated during the transition period in dairy cattle, when lipids are strongly mobilized from the adipose tissues to the bloodstream, with plasma concentrations increasing from the basal level of $0.1 \mathrm{mM}$ to $0.7-2 \mathrm{mM}$ [1, 25-27]. Until now, the involvement of G-coupled fatty acid receptors, such as FFAR1/GPR40, in the NEFA-mediated calcium response in primary endothelial cells has been unclear. This study has demonstrated that single NEFAs alone, at low concentrations of $0.3 \mathrm{mM}$, increase the intracellular calcium response in primary bovine endothelial cells, inducing different molecular pathways involved in the endothelial cell activation process. In naturally occurring acute systemic coliform mastitis linoleic acid and oleic acid were the most abundant NEFA, suggesting that specific fatty acids can be involved in inflammation and innate immunity, and to be relevant as risk factors during the transition period [28]. 

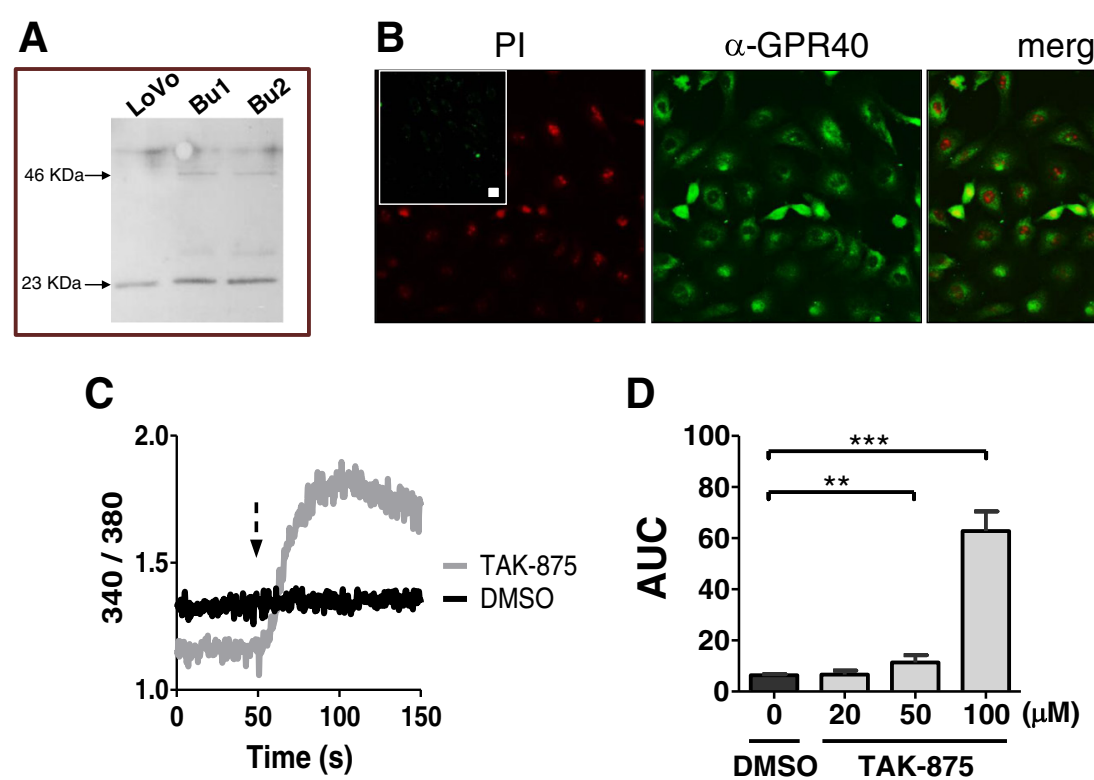

Fig. 3 Protein expression and functional detection of FFAR1/GPR40 in BUVEC monolayers. a Western blot of bovine FFAR1/GPR40. Total protein extract from LoVo cells was used as the positive control for two BUVEC isolates. $50 \mathrm{\mu g}$ of total protein was loaded onto a $6 \%$ polyacrylamide gel. b FFAR1/GPR40 immunofluorescence. Left image, nuclear signals of cells incubated with propidium iodide (PI); inset image: only the secondary antibody was used, as the negative control, bar $=20 \mu \mathrm{m}$. Middle image, FFAR1/GPR40 detected with rabbit anti-GPR40 antiserum and an antirabbit IgG secondary antibody. Right image, nuclear signals and GPR40 images are superimposed, bar $=20 \mathrm{~nm}$. c Representative time course of the Fura-2/AM ratio in BUVECs exposed to $1 \%$ DMSO or $100 \mu \mathrm{M}$ TAK-875 at the time indicated by the arrow. $\mathbf{d}$ Cells were exposed to DMSO or TAK-875. The area under the curve (AUC) was calculated during the first $100 \mathrm{~s}$ after exposure to the stimulus. The data are expressed as the means \pm SEM of at least three independent experiments. ${ }^{* *} p<0.01$, ${ }^{* *} p<0.005$

Different studies have reported the potency with which MA and LA bind to human FFAR1/GPR40 in transfected $\mathrm{CHO}$ and HEK293 cells by measuring the calcium signal. For $\mathrm{MA}, \mathrm{a} \mathrm{EC}_{50}$ value has been described in these cells, close to $7 \mu \mathrm{M}$, but for $\mathrm{LA}$, the $\mathrm{EC}_{50}$ values ranged from 1.8 to $6.6 \mu \mathrm{M}[11,12]$. In contrast, the $\mathrm{EC}_{50}$ values for MA and LA were 30.3 and $38.4 \mu \mathrm{M}$, respectively, in a reporter cell line based on HeLa cells transfected with hGPR40 [29]. These results are quite similar to those observed in the present study, especially regarding the stimulatory potency of LA. Because many of the effects of NEFAs on primary bovine endothelial cells could be attributed to bGPR40, including increased intracellular calcium influx, the presence of this specific NEFA receptor was assessed in BUVECs in this study. We detected FFAR1/GPR40 expression in BUVECs, and also evaluated its effect on the calcium flux using the agonist TAK-875 in our in vitro primary bovine endothelial cell system. There is some evidence that FFAR1/GPR40 is expressed in bovine cells and bovine FFAR1/GPR40 has been shown to share $84 \%$ nucleotide sequence identity with the human isoform [13, 14]. Previous studies have examined the expression of GPR40 in endothelial cells from monkey brain tissues [30], neuromicrovascular cells from rodent tissues [31], and human cardiac endothelial cells [32]. To the best of our knowledge, this work is the first to report the expression of GPR40 in primary bovine endothelial cells.

Our data also suggest that the MA-mediated increase in calcium occurs when MA binds to bGPR40, because it was clearly inhibited by GW1100, a potent FFAR1/ GPR40 antagonist. In contrast, the increase in calcium induced by LA does not involve this receptor, according to our antagonist experiments. We also observed that $\mathrm{IP}_{3}$ receptors/calcium-operated channels and LTCCs seem to participate in the cellular responses to MA and LA, respectively. Others have shown, that OA increased the calcium signal in HEK 293 cells transiently transfected with the $\alpha 1$ subunits of the LTCCs [23]. The pathway of calcium entry via the LTCCs induced by NEFAs is evidently cell-type dependent. LTCCs were also associated with the increase in calcium mediated by FFAR1/ GPR40 activation that was induced by the saturated fatty acid PA in rat $\beta$-cell line INS-1E [22], by the unsaturated fatty acid OA in islet $\beta$-cells from rats [33], and by LA in primary cultured chicken hepatocytes [34]. Our examination of the cellular calcium flux suggests that MA, but not LA, recognizes FFAR1/GPR40 in BUVECs. The CACNA2D1 gene encodes the alpha 2/delta subunit which is an accessory part of the voltage-gated calcium channel family (e.g., LTCC) and considered to be an important candidate protein influencing bovine mastitis 


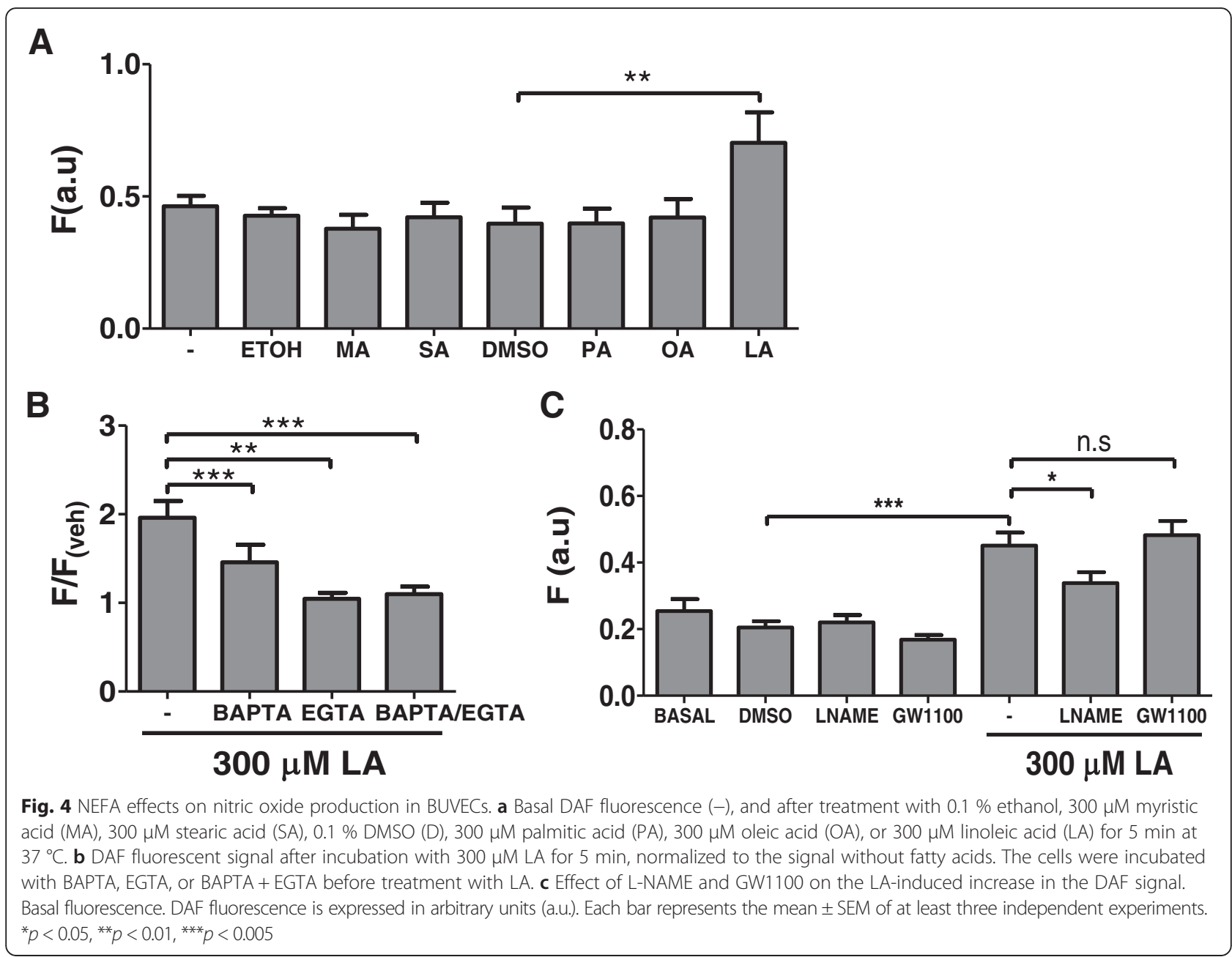

[35]. Although many publications have reported LTCC activity in bovine immune cells, there is not yet any evidence that these channels are expressed in bovine endothelial cells. In the present study, nifedipine affected BUVECs, suggesting the participation of LTCCs. It has also been recently demonstrated that the increase in calcium caused by endothelin-1 is LTCC-dependent in cultured bovine corneal endothelial cells [36].

We also evaluated the NO response in NEFA-exposed bovine endothelium, because NO is a well-known indicator of inflammation [37]. All NEFAs were evaluated, but only LA increased NO in the endothelial cells. This response was dependent on both calcium and eNOS. There is evidence that eNOS activity is dependent on $\mathrm{Ca}^{2+} /$ calmodulin [38], and it is probable that the increase in $\mathrm{NO}$ is a secondary effect after the interaction of eNOS with $\mathrm{Ca}^{+2} /$ calmodulin. Both NO and eNOS actively participate in the regulation of vascular tone and are therefore important intracellular enzymes, especially in microvascular hyperpermeability [39]. There is some evidence that increased levels of NO in endothelial cells produce proinflammatory profiles, which might lead to metabolic diseases. LA induces reactive oxygen species (ROS) and the overproduction of NO after an increase in calcium, causing peroxynitration in endothelial cells [40]. NF- $\kappa B$, a crucial transcription factor, is then activated by peroxynitrite, a potent oxidative agent, inducing the expression of adhesion molecules [40] and chemokines, such as IL-8 [41]. We also demonstrated that LA, but not MA, induces ICAM-1- and IL-8-expression, suggesting an active role for $\mathrm{NO}$ in this response. In bovine endothelial cell cultures, high concentrations of total NEFAs might increase ICAM-1 mRNA and protein expression [6]. The LA-induced adhesion molecules and chemokines may participate in leukocyte-endothelial cell interactions, facilitating transendothelial migration [42], and may play a role in the onset of a proinflammatory process during the transition period in dairy cattle. Massive lipid mobilization leading to an increase in plasma NEFAs is observed in cows around parturition, causing an increased incidence of metabolic and infectious diseases, including laminitis, endometritis, and mastitis 

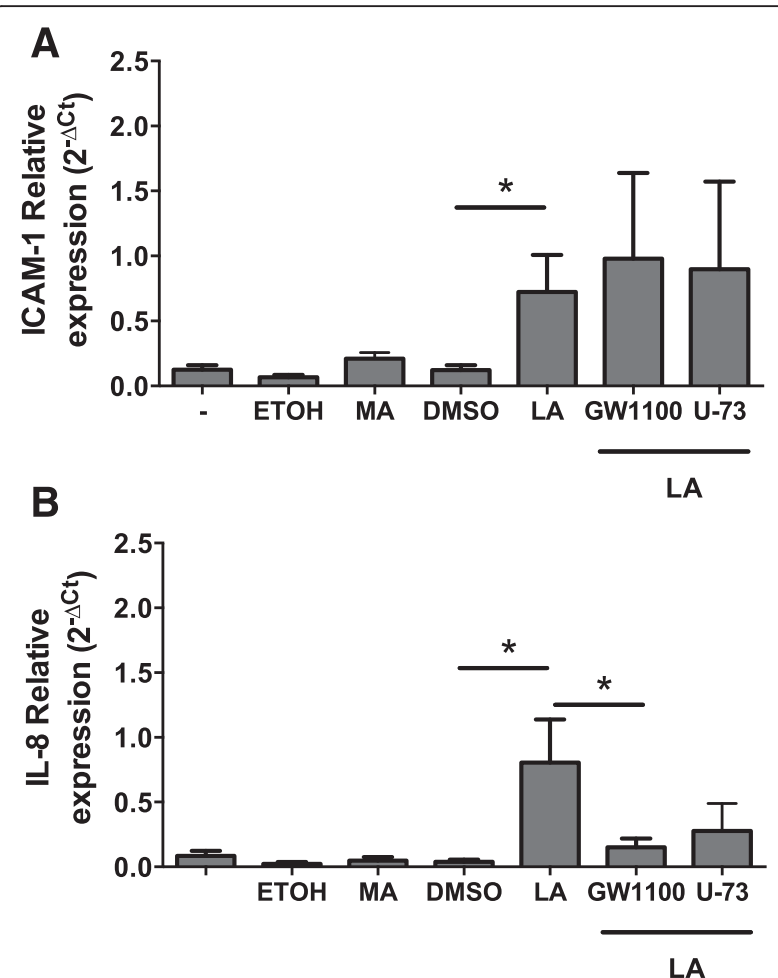

Fig. 5 NEFA effects on ICAM-1 and IL-8 expression in BUVECs. Cells were treated with $0.1 \%$ ethanol, $300 \mu \mathrm{M}$ myristic acid (MA), $0.1 \%$ DMSO, $300 \mu \mathrm{M}$ oleic acid (OA), or $300 \mu \mathrm{M}$ linoleic acid (LA) for $3 \mathrm{~h}$ and their RNAs were then isolated. Some cells were treated with $10 \mu \mathrm{M}$ GW1100 or $4 \mu \mathrm{M}$ U73122 (U-73) for 30 min before the LA treatment. The expression of ICAM-1 and IL-8 was analyzed with real-time PCR using specific primers. Relative abundance $=2^{-\Delta C t}$, where $\Delta \mathrm{Ct}=$ cycle treshold ICAM-1 or Ct IL-8 minus cycle treshold $\mathrm{SDHA}$. The data are expressed as the means \pm SEM of three experiments. ${ }^{*} p<0.05$

[1-4]. The exposure of bovine endothelial cells to NEFAs increases the expression of the proinflammatory cytokines IL-6 and IL-8 and the adhesion molecules ICAM-1 and VCAM-1 [6]. It has also been postulated that the excessive accumulation of NEFAs during chronic inflammatory responses might increase TNF $\alpha$, IL-6, and IL- $1 \beta$ expression by activating NF- $\mathrm{KB}$ in adipocytes and macrophages. These cytokines are thought to link the metabolic state and the inflammatory response, usually in the postpartum period within the uteri of cows $[3,4]$.

There is evidence that endothelial calcium participates in the transendothelial lymphocyte migration caused by ICAM-1 [43]. Moreover, an intracellular calcium increase has been related with ICAM-1 expression in HUVEC [44]. However, in BUVECs, intracellular calcium increase could be not directly associated with the expression of ICAM-1 or IL-8. Consistently with these assumption MA increased calcium flux was not sufficient to increase the expression of these molecules and the inhibition of PLC did not reduce the expression of ICAM-1 and IL-8 induced by LA. Our data also demonstrate that the individual NEFAs have different effects on endothelial cell activity and diverse mechanisms of action. LA induces the expression of ICAM-1 independently of FFAR1/GPR40 or PLC activity, although the expression of IL-8 is associated with the activation of FFAR1/GPR40 in BUVECs. In contrast, our results showed that NO was induced by LA, in a rather Gprotein-coupled-receptor-independent process. There is some evidence that these receptors need not bind to a G-protein in the presence of high agonist concentrations, which thereby alternatively activate the ERK/ MAPK pathway [45]. It has been suggested that LA activates the phosphoinositide 3-kinase, ERK1/2, and p-38 MAPK pathways in vascular endothelial cells [46]. In our laboratory, we have recently shown that the increase in NO caused by LA is p38-dependent (unpublished data). For this reason, it is possible that LA activates FFAR1/GPR40 or another receptor in a G-proteinindependent manner. For instance, we cannot exclude the possibility that the GPR120 receptor recognizes LA by another mechanism $[16,47]$, or that LA is recognized by GPR84, a medium-chain fatty acid receptor [48], or CD36, a fatty acid transporter protein [49, 50]. Only CD36 expression has been demonstrated in endothelial cells [51]. It has also been proposed that LA mobilizes intracellular calcium via an LA metabolite that induces intracellular mitochondrial calcium fluxes [52].

\section{Conclusions}

We have demonstrated for the first time in primary bovine endothelial cells that GPR40 is involved in the increase in calcium induced by MA, and conversely, that the LA calcium flux is not associated with this receptor. We have also demonstrated the participation of $\mathrm{IP}_{3}$ receptors/calcium-operated channels and LTCCs in the cellular responses to MA and LA. We observed FFAR1/ GPR40 expression in the bovine endothelium and confirmed its activity using its agonist, TAK-875. Only LA increased NO levels, and this was independent of FFAR1/GPR40. Only LA induced the expression of ICAM-1 and IL-8, and this phenomenon is a FFAR1/ GPR40- dependent cellular process. These results indicate that the responses of endothelial cells to individual NEFAs are highly variable. Recently, it has been demonstrated that there is an association of LA enhancement in plasma and milk in naturally occurring acute systemic coliform mastitis [52]. Therefore, the increase in total NEFAs that is described as risk factor for the onset of proinflammatory process that occur during transition periods in cattle, should be revised carefully in the future. Further studies are required to determine whether other individual NEFAs participate in the bovine proinflammatory 
responses in vivo during the transition period and in other NEFA-dependent disorders in cattle.

\section{Methods \\ Fatty acids}

We used those fatty acids that have shown changes during transition period [1]. Myristic and stearic acids were purchased from Sigma Chemical Co. (St. Louis, MO, USA) and suspended in $100 \%$ analytical-grade ethanol (Merck, Germany). Palmitic, oleic, and linoleic acids (Sigma Chemical Co. USA) were prepared in $100 \%$ DMSO (Sigma Chemical Co. USA). Stocks of single fatty acids were prepared at concentrations of $300 \mathrm{mM}$, protected from light, and stored at $-20{ }^{\circ} \mathrm{C}$. To estimate the calcium dose responses, the fatty acids were diluted to the indicated concentrations, with the vehicle maintained at $1 \%$ DMSO or $1 \%$ ethanol to avoid a possible dilution effect of vehicles. Because $300 \mu \mathrm{M}$ concentrations of all fatty acids were used in the NO experiments, $0.1 \%$ DMSO or $0.1 \%$ ethanol were used as the vehicles. Neither the DMSO nor ethanol concentration used for the calcium and NO assays affected the viability of BUVECs during period of exposure. The working stocks of fatty acids were maintained at $37{ }^{\circ} \mathrm{C}$ and were protected from light before to use.

\section{Cell culture}

Primary BUVECs were isolated from bovine umbilical cords according to Hermosilla et al. [53]. All bovine umbilical cords were obtained as part of natural parturition procedures at the Clinic for Obstetrics and Gynaecology and Andrology of Large and Small animals, Faculty of Veterinary Medicine, Justus Liebig University Giessen, Germany therefore no intervention was made or ethic approval was requested.

Briefly, the umbilical veins were isolated from the umbilical cords of calves born by cesarean section and kept at $4{ }^{\circ} \mathrm{C}$ in sterile $0.9 \%$ Hanks balanced salt solution HBSS-HEPES buffer (w/v; pH 7.4; Gibco, USA) supplemented with $1 \%$ penicillin $(\mathrm{v} / \mathrm{v} ; 500 \mathrm{U} / \mathrm{ml})$ and streptomycin (v/v; $500 \mu \mathrm{g} / \mathrm{ml}$, Sigma-Aldrich) until use. Under sterile conditions, one end of each umbilical cord vein was clamped shut, and $0.025 \%$ collagenase type II (w/v; Worthington Biochemicals Corporation, USA) in Puck's saline A solution (PSA; Gibco, USA) was gently infused into the vein lumens. After the remaining open ends of the umbilical veins were clamped, they were incubated at $37{ }^{\circ} \mathrm{C}$ in $5 \% \mathrm{CO}_{2}$ for $20 \mathrm{~min}$. The umbilical veins were then gently massaged and unclamped, and the resulting collagenase solutions were collected individually in $50 \mathrm{ml}$ plastic tubes (Nunc, USA) containing $1 \mathrm{ml}$ of fetal calf serum (FCS; Gibco) to inactivate the collagenase. The umbilical vein lumens were then washed twice with RPMI 1640 culture medium (Gibco). The washes were pooled, centrifuged $(400 \times g, 10 \mathrm{~min})$, resuspended in complete endothelial cell growth medium (ECGM; PromoCell, Germany), plated in $25 \mathrm{~cm}^{2}$ plastic tissue culture flasks (Nunc), and incubated at $37{ }^{\circ} \mathrm{C}$ in $5 \%$ $\mathrm{CO}_{2}$. The BUVEC monolayers were fed complete ECGM one day after isolation and then every 2-3 days thereafter. The purity of BUVEC was at least $97 \%$ and characterized by their typical cobblestone morphology and by the incorporation assay of Dil-Ac-LDL (dioactecyltetramethyl-indocarbocyanine perchlorate acetylated lowdensity lipoprotein) as described elsewhere, [54]. The cells were used for the NEFA experiments after 1-6 passages in vitro.

BUVEC cultures were fed three times a week with modified ECGM culture medium: 70 \% M199 (Gibco) with 30 \% complete ECGM supplemented with epithelial and endothelial growth factors, heparin (all from PromoCell), $2 \mathrm{mM}$ glutamine, $2 \%$ FCS, $100 \mathrm{U} / \mathrm{ml}$ penicillin, and $100 \mu \mathrm{g} / \mathrm{ml}$ streptomycin sulfate (HyClone, Thermo Scientific, USA). The cells were maintained at $37{ }^{\circ} \mathrm{C}$ in a $5 \% \mathrm{CO}_{2}$ atmosphere.

\section{Intracellular calcium measurement}

For the NEFA experiments, BUVEC monolayers were trypsinized with $0.25 \%$ trypsin/EDTA (Gibco) from plastic tissue culture plates (Life Technologies, USA), and $5 \times 10^{6}$ cells $/ \mathrm{ml}$ were suspended and incubated for 30 min at $37{ }^{\circ} \mathrm{C}$ in HEPES-buffered saline (HBS) buffer (concentrations in mM: $150 \mathrm{NaCl}, 5 \mathrm{KCl}, 1 \mathrm{CaCl}_{2}, 1$ $\mathrm{MgCl}_{2}, 20$ HEPES, 5 glucose, $\mathrm{pH}$ 7.4), supplemented with $10 \mu \mathrm{M}$ Fura-2-AM and $0.02 \%$ Pluronic F-127 (Invitrogen, Molecular Probes, USA). The unincorporated dye was removed twice with HBS buffer washes. The cells $(250,000$ cells $/ \mathrm{ml})$ were stored in HBS at $4{ }^{\circ} \mathrm{C}$, and then prewarmed for $5 \mathrm{~min}$ at $37{ }^{\circ} \mathrm{C}$. Fluorescence intensities were detected every $0.2 \mathrm{~s}$ at $509 \mathrm{~nm}$ emission and $340 / 380 \mathrm{~nm}$ dual-wavelength excitation in an LS55 spectrofluorometer (PerkinElmer Life Science, USA). The time course of FURA-2/AM in BUVECs was recorded as the ratio of the fluorescent signals without stimulus for $50 \mathrm{~s}$ and during exposure to each fatty acid for $100 \mathrm{~s}$. The area under curve (AUC) of calcium flux was calculated for the $100 \mathrm{~s}$ of NEFA exposure after background subtraction. The slopes of the increase in the calcium signal caused by fatty acids were calculated with a linear regression adjusted to the first $8 \mathrm{~s}$ of the fluorescent signal ratio (340/380) under basal and BAPTA-AM conditions.

\section{NO measurement}

Cells were trypsinized, as described above, seeded in a 96-well plate at a density of 20,000 cell/well, and cultured with $100 \mu \mathrm{l}$ of ECGM-supplemented medium (PromoCell). On day 3, the cells were washed gently once with HBS and incubated for $20 \mathrm{~min}$ at room 
temperature with $5 \mu \mathrm{M}$ DAF-FM and $0.02 \%$ pluronic acid (Invitrogen, Molecular Probes, USA). The unincorporated dye was removed by washing once with HBS. When the cells were pretreated before fatty acid exposure, they were incubated for $15 \mathrm{~min}$. The cells were then incubated with different NEFAs in the absence and presence of different treatments for $5 \mathrm{~min}$ at $37{ }^{\circ} \mathrm{C}$. The DAF-FM signals were then detected with a fluorescence multiplate reader (Varioskan ${ }^{\circ}$, Thermo Scientific) at $480 \mathrm{~nm}$ excitation/520 nm emission with light detection for $800 \mathrm{~ms}$.

To assess the roles of intracellular and extracellular calcium in the calcium flux and $\mathrm{NO}$ production in BUVECs, the cells were incubated for $30 \mathrm{~min}$ with $50 \mu \mathrm{M}$ BAPTA/AM at $37{ }^{\circ} \mathrm{C}$, then washed, and maintained in HBS. For the EGTA treatment, the cells were treated with HEPES-buffered saline without calcium, and EGTA $(0.3 \mathrm{mM})$ was added just before measurement [55].

\section{Immunoblotting}

BUVECs were lysed with a previously described method [53], and $50 \mu \mathrm{g}$ of total protein was loaded onto a $12 \%$ polyacrylamide gel and transferred to a nitrocellulose membrane at $100 \mathrm{~mA}$ for $1 \mathrm{~h}$. The nitrocellulose membrane was incubated with blocking buffer for $1 \mathrm{~h}$, and probed overnight at $4{ }^{\circ} \mathrm{C}$ with $0.001 \mu \mathrm{g} / \mu \mathrm{l}$ anti-humanGPR40 antiserum prepared in a rabbit (Abcam, USA). The membrane was washed three times in Tris-buffered saline and then exposed to 1:5000 anti-rabbit-IgG antibody conjugated with horseradish peroxidase (Cell Signaling) for $1 \mathrm{~h}$ at room temperature. Blocked antibody solutions were prepared with $1 \%$ fat-free milk phosphatebuffered saline (PBS)-Tween $0.1 \%$ (PBST), and signals were detected with an enhanced chemiluminescence system.

\section{Indirect immunofluorescence}

Cells were grown on $12 \mathrm{~mm}$ glass coverslips, fixed with $4 \%$ paraformaldehyde (Merck), permeabilized with $100 \mu \mathrm{M}$ digitonin (Sigma-Aldrich). They were incubated with $0.010 \mu \mathrm{g} / \mu \mathrm{l}$ anti-GPR40 antiserum (Abcam, USA) overnight at room temperature, and then with $0.4 \mu \mathrm{g} / \mu \mathrm{l}$ Alexa-Fluor-488-conjugated anti-rabbit IgG antibody (Calbiochem, USA) for $1 \mathrm{~h}$ at room temperature. The anti-GPR40 antiserum was raised against the human epitope, but this particular peptide region is conserved in bovine species, as the predictive sequence indicates [13]. This antibody has been used successfully in our laboratory, as described elsewhere [14]. The blocking and antibody solutions were prepared with $1 \%$ BSA-PBST (Sigma-Aldrich). Cell nuclei were stained with $0.1 \mu \mathrm{g} / \mu \mathrm{l}$ propidium iodide (Invitrogen, Molecular Probes, USA) diluted in PBS. The images were obtained on a Fluoview
$\mathrm{SV} 1000^{\circ}$ confocal microscope (Olympus) (Centre of Scientific Studies, Valdivia, Chile) equipped with a digital camera.

\section{Cell death assay}

Cells were seeded in 96-well plates at 20,000 cells $/ \mathrm{ml}$, and on day 3 , were washed gently with HBS before exposure to NEFAs for $15 \mathrm{~min}$ at $37{ }^{\circ} \mathrm{C}$. As the positive control for cell death, cells were treated with $0.2 \%$ Triton X-100 diluted in $\mathrm{HBS}$ at $37{ }^{\circ} \mathrm{C}$ for 15 min. BUVECs were treated with different single NEFAs $(300 \mu \mathrm{M}$ LA, PA, OA, MA, or SA), Triton X-100, or $1 \%$ vehicle (DMSO or ethanol). The cells were then incubated with $5 \mu \mathrm{M}$ propidium iodide (Molecular Probes, Invitrogen) in HBS for $15 \mathrm{~min}$. The propidium iodide signals were detected with a fluorescence multiplate reader (Varioskan', Thermo Scientific) at $530 \mathrm{~nm}$ excitation/620 nm emission.

\section{NEFA effects on adhesion molecule expression in BUVECs} To determine the effects of NEFAs on the expression of adhesion molecules, confluent BUVEC monolayers were treated with $300 \mu \mathrm{M}$ MA or vehicle ( $0.1 \%$ ethanol), or $300 \mu \mathrm{M}$ OA, $300 \mu \mathrm{M}$ LA, or vehicle (0.1\% DMSO) for $3 \mathrm{~h}$ and their total RNA was then isolated. In another set of experiments, BUVECs were preincubated with $10 \mu \mathrm{M}$ GW1100 or $4 \mu \mathrm{M}$ U73122 for $30 \mathrm{~min}$ before LA treatment.

\section{RNA isolation and RT-PCR analysis}

Total RNA was isolated from BUVECs with the E.Z.N.A Total RNA Kit ${ }^{\circ}$ (Omega Bio-Tek, Norcross, GA, USA), according to the manufacturer's instructions. The samples were treated with ribonuclease-free deoxyribonuclease I (Turbo DNA-free Kit, Ambion, UK) to remove any genomic DNA, and the RNA was quantified with a NanoDrop 2000 spectrophotometer (Thermo Fisher Scientific). For cDNA synthesis, 200 ng of RNA was reverse transcribed in the presence or absence of M-MLV reverse transcriptase (Promega). The PCR reaction was performed with Maxima SYBR Green/ROX qPCR Master Mix and $1 \mu \mathrm{L}$ of $\mathrm{cDNA}$. The primers for ICAM-1 and IL-8 used in this study were designed previously $[15,53]$. SDHA cDNA was also amplified as the housekeeping control [56].

\section{Statistical analysis}

The results are illustrated in bar graphs as the means \pm SEM of at least four independent experiments. Student's $t$ test or one-way analysis of variance and Dunnett's multiple comparison test were performed with a significance level of $5 \%$, using GraphPad Prism for Mac OS X (ver. 5.0; GraphPad Software, USA). 


\section{Additional files}

Additional file 1: NEFA treatment did not affect BUVEC cell viability. Cells were incubated for $15 \mathrm{~min}$ in the presence of HBS alone (basal), 0.3 mM EGTA (in HBS), solvent (DMSO or ethanol), $300 \mu \mathrm{M}$ of each fatty acid or $300 \mu \mathrm{M}$ fatty acid plus EGTA. In other experimental set, cells also were incubated for 30 min with $50 \mu \mathrm{M}$ BAPTA-AM in HBS and then exposed to each fatty acid for $15 \mathrm{~min}$. Afterwards, the cells were exposed to propidium iodide in HBS for 15 min. The signals of the incorporated propidium iodide were detected with a fluorescence multiplate reader in arbitrary units of fluorescence. Each bar represents the mean \pm SEM of at least three independent experiments. Myristic acid $(M A)$, palmitic acid (PA), stearic acid (SA), linoleic acid (LA), oleic acid $(O A)$ ** $p<0.05$ compared with basal. (PPT $128 \mathrm{~kb}$ )

Additional file 2: Effects of BAPTA and EGTA treatments on the slope of the Fura-2/AM signal in cells treated with myristic acid (MA) palmitic acid (PA), stearic acid (SA), linoleic acid (LA), or oleic acid (OA). Data are means \pm standard deviations; NS: not significant. (DOC 29 kb)

Additional file 3: Effect of GW110 on the increase in the area under curve of Fura-2/AM, induced with myristic acid (MA) palmitic acid (PA), stearic acid (SA), linoleic acid (LA), or oleic acid (OA). Data are means \pm standard deviations; NS: not significant. (DOC 33 kb)

\section{Abbreviations}

BAPTA-AM: 1,2-Bis(2-aminophenoxy)ethane-N,N,N',N'-tetraacetic acid tetrakis(acetoxymethyl ester); BSA: bovine serum albumin; BUVEC: bovine umbilical vein endothelial cells; DMSO: dimethyl sulfoxide; EGTA: ethylene glycol-bis-(2-aminoethyl)-N,N,N', N'- tetraacetic acid; eNOS: endothelial nitric oxide synthase; ETOH: ethanol; FFAR1: free fatty acid receptor 1; GPR40: G protein-coupled receptor 40; HBS: HEPES buffered saline; HBSS: Hank's balanced salt solution; ICAM-1: intercellular adhesion molecule 1; IL-8: interleukin 8; LA: linoleic acid; LTCC: L-type of calcium channels; MA: myristic acid; NEFA: non-esterified fatty acid; NO: nitric oxide; OA: oleic acid; PA: palmitic acid; PTX: Pertuxis toxin; SA: stearic acid; VCAM-1: vascular cell adhesion molecule 1.

\section{Competing interests}

The authors declare that they have no competing interests.

\section{Authors' contributions}

AL took part in all the experiments, MDC helped to carry out RT-PCR experiments, RBA and MAH helped to write the manuscript. RBA and AL designed all the experiments. AT and CH participated in the BUVEC isolation, cell culture and helped in RT-PCR. All authors have read and approved the final manuscript.

\section{Acknowledgements}

This work was supported by FONDECYT grants 3120255, 1120718, 1151047 and FONDEF IDeA grant ID14I10050. The authors would like to thank Felipe Barros for granting access to the confocal microcopy unit in the CECS, Valdivia, Chile, and Francisco Morera for substantial discussions and encouraging words in developing this research.

\section{Author details}

${ }^{1}$ Instituto de Farmacología, Facultad de Ciencias Veterinarias, Universidad Austral de Chile, Valdivia, Chile. ${ }^{2}$ Institute of Parasitology, Faculty of Veterinary Medicine, Justus Liebig University Giessen, Giessen, Germany.

Received: 26 May 2015 Accepted: 15 February 2016

Published online: 25 February 2016

\section{References}

1. Contreras GA, O'Boyle NJ, Herdt TH, Sordillo LM. Lipomobilization in periparturient dairy cows influences the composition of plasma nonesterified fatty acids and leukocyte phospholipid fatty acids. J Dairy Sci. 2010;93(6):2508-16.
2. Contreras GA, Sordillo LM. Lipid mobilization and inflammatory responses during the transition period of dairy cows. Comp Immunol Microbiol Infect Dis. 2011;34(3):281-9.

3. LeBlanc SJ. Interactions of metabolism, inflammation, and reproductive tract health in the postpartum period in dairy cattle. Reprod Domest Anim. 2012:47:18-30.

4. Sordillo LM, Raphael W. Significance of metabolic stress, lipid mobilization, and inflammation on transition Cow disorders. Vet Clin North Am Food Anim Pract. 2013;29(2):267-78.

5. Cook-Mills JM, Deem TL. Active participation of endothelial cells in inflammation. J Leukoc Biol. 2005;77(4):487-95.

6. Contreras GA, Raphael W, Mattmiller SA, Gandy J, Sordillo LM. Nonesterified fatty acids modify inflammatory response and eicosanoid biosynthesis in bovine endothelial cells. J Dairy Sci. 2012;95(9):5011-23.

7. Lacetera N, Scalia D, Franci O, Bernabucci U, Ronchi B, Nardone A. Short communication: effects of nonesterified fatty acids on lymphocyte function in dairy heifers. J Dairy Sci. 2004;87(4):1012-4.

8. Scalia D, Lacetera N, Bernabucci U, Demeyere K, Duchateau L, Burvenich C. In vitro effects of nonesterified fatty acids on bovine neutrophils oxidative burst and viability. J Dairy Sci. 2006;89(1):147-54

9. Hajri T, Abumrad NA. Fatty acid transport across membranes: relevance to nutrition and metabolic pathology. Annu Rev Nutr. 2002;22:383-415.

10. Kremmyda LS, Tvrzicka E, Stankova B, Zak A. Fatty acids as biocompounds: their role in human metabolism, health and disease - a review. Part 2: fatty acid physiological roles and applications in human health and disease. Biomed Pap. 2011;155(3):195-218

11. Itoh Y, Kawamata Y, Harada M, Kobayashi M, Fujii R, Fukusumi S, Ogi K, Hosoya M, Tanaka Y, Uejima H, et al. Free fatty acids regulate insulin secretion from pancreatic beta cells through GPR40. Nature. 2003;422(6928):173-6.

12. Briscoe CP, Tadayyon M, Andrews JL, Benson WG, Chambers JK, Eilert MM, Ellis C, Elshourbagy NA, Goetz AS, Minnick DT, et al. The orphan G proteincoupled receptor GPR40 is activated by medium and long chain fatty acids. J Biol Chem. 2003;278(13):11303-11.

13. Yonezawa $T$, Haga S, Kobayashi $Y$, Katoh K, Obara Y. Unsaturated fatty acids promote proliferation via ERK1/2 and Akt pathway in bovine mammary epithelial cells. Biochem Bioph Res Co. 2008;367(4):729-35.

14. Hidalgo MA, Nahuelpan C, Manosalva C, Jara E, Carretta MD, Conejeros I, Loaiza A, Chihuailaf R, Burgos RA. Oleic acid induces intracellular calcium mobilization, MAPK phosphorylation, superoxide production and granule release in bovine neutrophils. Biochem Bioph Res Co. 2011;409(2):280-6.

15. Mena J, Manosalva C, Ramirez R, Chandia L, Carroza D, Loaiza A, Burgos RA, Hidalgo MA. Linoleic acid increases adhesion, chemotaxis, granule release, intracellular calcium mobilisation, MAPK phosphorylation and gene expression in bovine neutrophils. Vet Immunol Immunopathol. 2013;151(3-4):275-84.

16. Briscoe CP, Peat AJ, McKeown SC, Corbett DF, Goetz AS, Littleton TR, McCoy DC, Kenakin TP, Andrews JL, Ammala C, et al. Pharmacological regulation of insulin secretion in MIN6 cells through the fatty acid receptor GPR40: identification of agonist and antagonist small molecules. Br J Pharmacol. 2006;148(5):619-28.

17. Bokoch GM, Katada T, Northup JK, Hewlett EL, Gilman AG. Identification of the predominant substrate for ADP-ribosylation by islet activating protein. J Biol Chem. 1983;258(4):2072-5.

18. Bleasdale JE, Thakur NR, Gremban RS, Bundy GL, Fitzpatrick FA, Smith RJ Bunting S. Selective inhibition of receptor-coupled phospholipase Cdependent processes in human platelets and polymorphonuclear neutrophils. J Pharmacol Exp Ther. 1990;255(2):756-68.

19. Bishara NB, Murphy TV, Hill MA. Capacitative $\mathrm{Ca}(2+)$ entry in vascular endothelial cells is mediated via pathways sensitive to 2 aminoethoxydiphenyl borate and xestospongin $\mathrm{C}$. Br J Pharmacol. 2002:135(1):119-28.

20. Bootman MD, Collins TJ, Mackenzie L, Roderick HL, Berridge MJ, Peppiatt CM. 2-aminoethoxydiphenyl borate (2-APB) is a reliable blocker of storeoperated Ca2+ entry but an inconsistent inhibitor of InsP3-induced Ca2+ release. FASEB J. 2002;16(10):1145-50.

21. Putney JW. Pharmacology of Store-operated Calcium Channels. Mol Interv. 2010;10(4):209-18

22. Shapiro H, Shachar S, Sekler I, Hershfinkel M, Walker MD. Role of GPR40 in fatty acid action on the beta cell line INS-1E. Biochem Bioph Res Co. 2005;335(1):97-104. 
23. Tian YR, Corkey RF, Yaney GC, Goforth PB, Satin LS, de Vargas LM. Differential modulation of L-type calcium channel subunits by oleate. Am J Physiol Endoc M. 2008;294(6):E1178-86.

24. Negoro N, Sasaki S, Mikami S, Ito M, Suzuki M, Tsujihata Y, Ito R, Harada A, Takeuchi K, Suzuki N, et al. Discovery of TAK-875: a potent, selective, and orally bioavailable GPR40 agonist. Acs Med Chem Lett. 2010;1 (6):290-4

25. Douglas GN, Rehage J, Beaulieu AD, Bahaa AO, Drackley JK. Prepartum nutrition alters fatty acid composition in plasma, adipose tissue, and liver lipids of periparturient dairy cows. J Dairy Sci. 2007;90(6):2941-59.

26. Leroy JLMR, Vanholder T, Mateusen B, Christophe A, Opsomer G, de Kruif A, Genicot G, Van Soom A. Non-esterified fatty acids in follicular fluid of dairy cows and their effect on developmental capacity of bovine oocytes in vitro. Reproduction. 2005;130(4):485-95.

27. Melendez P, Marin MP, Robles J, Rios C, Duchens M, Archbald L. Relationship between serum nonesterified fatty acids at calving and the incidence of periparturient diseases in Holstein dairy cows. Theriogenology. 2009:72(6):826-33.

28. Mavangira V, Gandy JC, Zhang C, Ryman VE, Daniel Jones A, Sordillo LM. Polyunsaturated fatty acids influence differential biosynthesis of oxylipids and other lipid mediators during bovine coliform mastitis. J Dairy Sci. 2015;98(9):6202-15.

29. Kotarsky K, Nilsson NE, Flodgren E, Owman C, Olde B. A human cell surface receptor activated by free fatty acids and thiazolidinedione drugs. Biochem Bioph Res Co. 2003;301(2):406-10.

30. Ma D, Lu L, Boneva NB, Warashina S, Kaplamadzhiev DB, Mori Y, Nakaya MA Kikuchi $\mathrm{M}$, Tonchev AB, Okano $\mathrm{H}$, et al. Expression of free fatty acid receptor GPR40 in the neurogenic niche of adult monkey hippocampus. Hippocampus. 2008;18(3):326-33.

31. Honore JC, Kooli A, Hamel D, Alquier T, Rivera JC, Quiniou C, Hou X, Kermorvant-Duchemin E, Hardy P, Poitout V, et al. Fatty acid receptor Gpr40 mediates neuromicrovascular degeneration induced by transarachidonic acids in rodents. Arterioscl Throm Vas. 2013:33(5):954-U202.

32. Lu ZY, Li YC, Jin JF, Zhang XM, Hannun YA, Huang Y. GPR40/FFA1 and neutral sphingomyelinase are involved in palmitate-boosted inflammatory response of microvascular endothelial cells to LPS. Atherosclerosis. 2015;240(1):163-73.

33. Fujiwara K, Maekawa F, Yada T. Oleic acid interacts with GPR40 to induce $\mathrm{Ca} 2+$ signaling in rat islet beta-cells: mediation by PLC and L-type Ca2+ channel and link to insulin release. Am J Physiol Endocrinol Metab. 2005;289(4):E670-677.

34. Suh $\mathrm{HN}$, Huong $\mathrm{HT}$, Song $\mathrm{CH}$, Lee $\mathrm{H}$, Han HJ. Linoleic acid stimulates gluconeogenesis via $\mathrm{Ca} 2+/ \mathrm{PLC}, \mathrm{CPLA}(2)$, and PPAR pathways through GPR40 in primary cultured chicken hepatocytes. Am J Physiol Cell Ph. 2008;295(6):C1518-27

35. Deb R, Singh U, Kumar S, Kumar A, Singh R, Sengar G, Mann S, Sharma A. Genotypic to expression profiling of bovine calcium channel, voltagedependent, alpha-2/delta subunit 1 gene, and their association with bovine mastitis among Frieswal (HFX Sahiwal) crossbred cattle of Indian origin. Anim Biotechnol. 2014;25(2):128-38.

36. Hong SJ, Wu KY, Wang HZ, Fong JC. Change of cytosolic Ca2+ mobility in cultured bovine corneal endothelial cells by endothelin-1. J Ocul Pharmacol Th. 2003;19(1):1-9.

37. Torreilles J. Nitric oxide: One of the more conserved and widespread signaling molecules. Front Biosci. 2001;6:D1161-72.

38. Fleming I, Busse R. Signal transduction of eNOS activation. Cardiovasc Res. 1999:43(3):532-41.

39. Sanchez FA, Rana R, Gonzalez FG, Iwahashi T, Duran RG, Fulton DJ, Beuve AV, Kim DD, Duran WN. Functional Significance of Cytosolic Endothelial Nitric-oxide Synthase (eNOS) REGULATION OF HYPERPERMEABILITY. J Biol Chem. 2011;286(35):30409-14.

40. Saraswathi V, Wu GY, Toborek M, Hennig B. Linoleic acid-induced endothelial activation: role of calcium and peroxynitrite signaling. J Lipid Res. 2004;45(5):794-804.

41. Kofler S, Nickel T, Weis M. Role of cytokines in cardiovascular diseases: a focus on endothelial responses to inflammation. Clin Sci (Lond). 2005;108(3):205-13.

42. Lawson C, Wolf S. ICAM-1 signaling in endothelial cells. Pharmacol Rep. 2009;61(1):22-32.

43. Etienne-Manneville S, Manneville JB, Adamson P, Wilbourn B, Greenwood J, Couraud PO. ICAM-1-coupled cytoskeletal rearrangements and transendothelial lymphocyte migration involve intracellular calcium signaling in brain endothelial cell lines. J Immunol. 2000;165(6):3375-83.
44. Barnett Jr CC, Moore EE, Silliman CC, Abdalla EK, Partrick DA, Curley SA. Cytosolic phospholipase A(2)-mediated ICAM-1 expression is calcium dependent. J Surg Res. 2001;99:307-10.

45. Sun $Y$, McGarrigle D, Huang XY. When a G protein-coupled receptor does not couple to a G protein. Mol Biosyst. 2007;3(12):849-54.

46. Hennig B, Lei W, Arzuaga X, Das Ghosh D, Saraswathi V, Toborek M. Linoleic acid induces proinflammatory events in vascular endothelial cells via activation of PI3K/Akt and ERK1/2 signaling. J Nutr Biochem. 2006;17(11):766-72.

47. Watson SJ, Brown AJH, Holliday ND. Differential signaling by splice variants of the human free fatty acid receptor GPR120. Mol Pharmacol. 2012:81(5):631-42

48. Wang JH, Wu XS, Simonavicius N, Tian H, Ling L. Medium-chain fatty acids as ligands for orphan $\mathrm{G}$ protein-coupled receptor GPR84. J Biol Chem. 2006;281(45):34457-64

49. Gaillard D, Laugerette F, Darcel N, El-Yassimi A, Passilly-Degrace P, Hichami A, Khan NA, Montmayeur JP, Besnard P. The gustatory pathway is involved in CD36-mediated orosensory perception of long-chain fatty acids in the mouse. FASEB J. 2008;22(5):1458-68.

50. Ozdener MH, Subramaniam $\mathrm{S}$, Sundaresan $\mathrm{S}$, Sery $\mathrm{O}$, Hashimoto $T$, Asakawa Y, Besnard P, Abumrad NA, Khan NA. CD36-and GPR120-mediated Ca2+ signaling in human taste Bud cells mediates differential responses to fatty acids and is altered in obese mice. Gastroenterology. 2014;146(4):995-U544.

51. Kerkhoff C, Sorg C, Tandon NN, Nacken W. Interaction of S100A8/S100A9 Arachidonic acid complexes with the scavenger receptor CD36 may facilitate fatty acid uptake by endothelial cells. Biochemistry. 2001;40(1):241-8.

52. Zhao YF, Wang L, Qiu JH, Zha DJ, Sun Q, Chen C. Linoleic acid stimulates $[\mathrm{Ca} 2+] \mathrm{i}$ increase in Rat pancreatic beta-cells through both membrane receptor- and intracellular metabolite-mediated pathways. Plos One. 2013:8(4):e60255.

53. Hermosilla C, Zahner H, Taubert A. Eimeria bovis modulates adhesion molecule gene transcription in and PMN adhesion to infected bovine endothelial cells. Int J Parasitol. 2006;36(4):423-31.

54. Taubert A, Hermosilla C. Bovine recombinant IFNgamma induces endothelial cell gene transcription of immunoregulatory molecules and upregulates PMN and PBMC adhesion on bovine endothelial cells. Vet Res Commun. 2008;32(1):35-47.

55. Sandoval AJ, Riquelme JP, Carretta MD, Hancke JL, Hidalgo MA, Burgos RA Store-operated calcium entry mediates intracellular alkalinization, ERK1/2, and Akt/PKB phosphorylation in bovine neutrophils. J Leukocyte Biol. 2007:82(5):1266-77.

56. De Ketelaere A, Goossens K, Peelman L, Burvenich C. Technical note: validation of internal control genes for gene expression analysis in bovine polymorphonuclear leukocytes. J Dairy Sci. 2006;89(10):4066-9.

\section{Submit your next manuscript to BioMed Central and we will help you at every step:}

- We accept pre-submission inquiries

- Our selector tool helps you to find the most relevant journal

- We provide round the clock customer support

- Convenient online submission

- Thorough peer review

- Inclusion in PubMed and all major indexing services

- Maximum visibility for your research

Submit your manuscript at www.biomedcentral.com/submit 